\title{
Editorial \\ Who Wants a Blind Breast Surgeon?
}

\author{
William C. Dooley, MD
}

The University of Oklahoma Breast Institute, 920 S. L. Young Boulevard, Suite 2290, Oklahoma City, Oklahoma 73104, USA

Mammary ductoscopy was introduced by Japanese surgeons in the early 1990s for the direct visualization of the source of bloody nipple discharge. ${ }^{1}$ As techniques and equipment have evolved in the last 15 years, we now have several relatively simple submillimeter endoscopes that can be used to look within saline-distended larger ductal segments within the breast. ${ }^{2-6}$ Valdes et al. ${ }^{7}$ demonstrate in their early experience with ductoscopy the ability to find and visualize intraductal lesions for excision. As with prior studies, they were impressed with the ability to identify histologically significant lesions that were relatively distant from the nipple, such as an $8-\mathrm{cm}-$ deep ductal carcinoma-in-situ. They clearly have increased the number of breast cancers identified before traditional radiographical imaging or clinical examination alone. From their study and others, it is not a giant leap to conclude that intraluminal abnormalities in the ductal system have just as much need to undergo biopsy as the average palpable lump or radiographical (mammographic, ultrasound, or magnetic resonance imaging) lesion. ${ }^{4,6,8-13}$ But this relatively narrow view misses the greatest power of this new technology.

We do not have mammogram and magnetic resonance imaging machines in our operating rooms to direct our surgical procedures. The best we can do is preoperative needle localization and postexcision specimen imaging. Despite this, most breast surgery operations today are performed with the same intraoperative imaging tool that Halsted used: the

Received January 26, 2006; accepted February 1, 2006; published online July 8, 2008.

Address correspondence and reprint requests to: William C. Dooley, MD; E-mail: william-dooley@ouhsc.edu.

Published by Springer Science+Business Media, Inc. @ 2008 The Society of Surgical Oncology, Inc. surgeon's palpation alone. The last decade has seen a rapid increase in intraoperative ultrasonography use by dedicated breast surgeons to assist in better and more accurate excisions of small invasive cancers. Improving our intraoperative mapping of the suspicious lesions - especially if these are potentially ductal carcinoma-in-situ - can only further enhance our success at getting truly clear margins. ${ }^{4-18}$ We understand that many cancers are years in evolution. We should not be waiting to treat them until they are invasive and have the potential to spread from the breast. Finding cancers earlier and intervening sooner has been the mantra that has led to the dramatic decreases in breast cancer death rates in the last several years.

Over the last decade, we have learned the importance of ellictable fluid from the nipple, especially in high-risk individuals. If we know someone is high risk and she is having breast surgery, should we not be certain that any intraductal lesions, related or unrelated to the target of the surgical procedure, are also adequately sampled? Can we perform a more accurate lumpectomy by actually mapping out the extent of the involved ductal system and either excising it all or excising the lesion and all associated intraluminal defects? When vascular surgeons are sewing on small blood vessels, is there any argument about putting on loops to make a better and smoother suture line closure? Although there are many unanswered questions about when and how best to use our new ability to see submillimeter disease with the new ductoscopes, there is no reason for surgeons to continue to blindly operate on the breast if their vision of the extent of intraluminal ductal lesions can be improved. My personal series of using ductoscopy to direct lumpectomy margins has consistently shown a marked decrease in positive margins at first excision. Although we are still following these patients up for 
long enough to achieve adequate statistical power of adequate woman-years of follow-up, the hazard rate for local recurrence in endoscopically directed lumpectomy appears to be less than one fifth that of cases performed either where endoscopy was not technically feasible or before the availability of endoscopy. ${ }^{14}$

We desperately need more research into the entire spectrum of the intraductal approach to understand how best to use these new technologies to prevent or treat even earlier breast cancers. We did not learn the value of earlier detection and excision of melanoma by not looking for smaller lesions. Now that we have tools to see breast intraductal lesions well less than one tenth the size of any seen by any current radiographical imaging, we need to know which ones are important to excise, which can be followed up, and which predict future malignancy. We will never know these important answers unless more of us start to look for these small lesions in our routine surgical breast care and document our findings. We can all congratulate Valdes et al. $^{7}$ for doing just that!

\section{REFERENCES}

1. Okazaki A, Okazaki M, Asaishi K, et al. Fiberoptic ductoscopy of the breast: a new diagnostic procedure for nipple discharge. Jpn J Clin Oncol 1991; 21:188-93.

2. Matsunaga T, Ohta D, Misaka T, et al. Mammary ductoscopy for diagnosis and treatment of intraductal lesions of the breast. Breast Cancer 2001; 8:213-21.

3. Kothari A, Beechey-Newman N, Kulkarni D. Breast duct micro-endoscopy: a study of technique and a morphological classification of endo-luminal lesions. Breast 2006; 15(3):363-9.
4. Beechey-Newman N, Kulkarni D, Kothari A, et al. Breast duct microendoscopy in nipple discharge: microbrush improves cytology. Surg Endosc 2005; 19:1648-51.

5. Jacobs VR, Kiechle M, Plattner B, et al. Breast ductoscopy with a $0.55-\mathrm{mm}$ mini-endoscope for direct visualization of intraductal lesions. J Minim Invasive Gynecol 2005; 12:359-64.

6. Dooley WC, Francescatti D, Clark L, Webber G. Office-based breast ductoscopy for diagnosis. Am J Surg 2004; 188:415-8.

7. Valdes EK, Boolbol SK, Cohen J-M, Balassanian R, Feldman SM. Clinical experience with mammary ductoscopy. Ann Surg Oncol. DOI: 10.1245/ASO.2006.08.025.

8. Moncrief RM, Nayar R, Diaz LK, et al. A comparison of ductoscopy-guided and conventional surgical excision in women with spontaneous nipple discharge. Ann Surg 2005; 241:575-81.

9. Sauter ER, Ehya H, Klein-Szanto AJ, et al. Fiberoptic ductoscopy findings in women with and without spontaneous nipple discharge. Cancer 2005; 103:914-21.

10. Matsunaga T, Kawakami Y, Namba K, Fujii M. Intraductal biopsy for diagnosis and treatment of intraductal lesions of the breast. Cancer 2004; 101:2164-9.

11. Sauter ER, Klein-Szanto A, Ehya H, MacGibbon B. Ductoscopic cytology and image analysis to detect breast carcinoma. Cancer 2004; 101:1283-92.

12. Sauter ER, Ehya H, Schlatter L, MacGibbon B. Ductoscopic cytology to detect breast cancer. Cancer J 2004; 10:33-41.

13. Yamamoto D, Senzaki H, Nakagawa H, et al. Detection of chromosomal aneusomy by fluorescence in situ hybridization for patients with nipple discharge. Cancer 2004; 97:690-4.

14. Dooley WC. Routine operative breast endoscopy during lumpectomy. Ann Surg Oncol 2003; 10:38-42.

15. Dooley WC. Routine operative breast endoscopy for bloody nipple discharge. Ann Surg Oncol 2002; 9:920-3.

16. Kim JA, Crowe JP, Woletz J, et al. Prospective study of intraoperative mammary ductoscopy in patients undergoing partial mastectomy for breast cancer. Am J Surg 2004; 188:411-4.

17. Sharma R, Dietz J, Wright $\mathrm{H}$, et al. Comparative analysis of minimally invasive microductectomy versus major duct excision in patients with pathologic nipple discharge. Surgery 2005; 138:591-6.

18. Dietz JR, Crowe JP, Grundfest S, et al. Directed duct excision by using mammary ductoscopy in patients with pathologic nipple discharge. Surgery 2002; 132:582-7. 